\title{
Can the people in poor countries benefit from science?
}

During the $20^{\text {th }}$ century, science has become increasingly important in world culture as well as in economics. In the new millennium, the sequencing of many organisms has started a new era with fascinating implications for the future. Much attention was drawn to such efforts for example by the publication of the working draft of the human genome in February 2001 (International Human Genome Sequencing Consortium 2001, Venter et al. 2001). Yet many other organisms have been sequenced or are currently being sequenced. The best known finished model organisms include Drosophila melanogaster (Adams et al. 2000), Caenorhabditis elegans (The C. elegans Sequencing Consortium 1998) or Arabidopsis thaliana (The Arabidopsis Genome Initiative 2000). There is no doubt that such projects will dramatically influence the course of the biological sciences, but more importantly the course of the human civilization.

On the one side, there are enormous advances in science; on the other, there is still too much poverty in the world. The poverty of the world or rather the poverty of many people can be documented by the following facts: 1.2 billion people live on less than a dollar per day, 1 billion people do not have access to clean water, more than 2 billion people have no access to adequate sanitation, hundreds of million poor farmers have difficulty maintaining the fertility of soils from which they eke out a meager living. Yet, the human population is increasing by 80 million persons a year, mostly in the poorest countries (Serageldin 2002).

Clearly, science has become the privilege of rich countries. While there are several dozen scientists per 10000 persons in the rich countries (e.g. 69 in USA), there are only a few in the poor ones. The enormous differences are also illustrated by the fact that the 47 least developed countries of the world, representing $10 \%$ of the world's population, subsist on less than $0.5 \%$ of the world's income. Even worse, an alarming number of approximately 40000 people die from hunger-related causes every day. Yet, the top $20 \%$ of the world's population consumes $85 \%$ of the world's income. The richest three persons have more wealth than the combined gross domestic product (GDP) of the 47 poorest countries and the richest 15 persons have more wealth than the combined GDP of all subSaharan Africa with its 550 million people (Serageldin 2002). Of the half million women, who die annually due to pregnancy or childbirth, $99 \%$ of cases occur in low- and middle income countries. In 1998, 1.6 million deaths were reported to be caused by diseases routinely vaccinated against in wealthy countries (Jha et al. 2002).

Currently poor countries cannot afford to pay many scientists and often the high-quality scientists leave for rich countries. But even if the science is done mostly in the rich countries, does it bring any benefit to the whole world? Would it not be more appropriate to use the money currently invested in research to protect people from starvation? Is it not too bizarre to be interested in knowing more about genes if there are millions of people who desperately need such money just to survive? Or can we ultimately make better living on this planet through science?

Firstly, there is no power and justification for taking money from one country to another for whatever reason. Secondly, rich countries also contribute to help poor countries from serious problems, although whether they are doing enough could be discussed at length. I think that it is very likely that people in rich countries will benefit more from sequencing the human genome than the people in the poor ones simply because the people in the poor countries often cannot afford the current medication not to speak of expensive and complicated health care or gene therapy.

Nevertheless, there is also one important finding that even the poorest countries might benefit from. The draft genome sequences of two major subspecies of rice (indica and japonica) have been published recently (Goff et al. 2002, Yu et al. 2002). Rice has been a staple of the human diet for many thousands years - currently one-third of the world's population relies on rice for a significant portion of their food. About $11 \%$ of the world's arable land is used for growing rice, and approximately $29 \%$ of total cereal production in 2000 was rice.

Up to now, humans have promoted development of desirable traits in the crops through selective breeding for many thousands of years. But explicit knowledge of gene function and its control (e.g. transcriptional) that cause these traits will allow more precise control of such traits and speedier change. For example the nutritional qualities of the grain can be improved, such as rice grains engineered to express precursors to vitamin A. Improving the plant's intrinsic resistance to 


\section{Discussion}

certain diseases can lessen the ecological impact of pesticide use and limited crop yields (Ronald and Leung 2002).

In addition, the information derived from the rice genome can be a useful guidance to the larger genomes of e.g. maize and barley. This will very likely create a short cut to the isolation of genes of agronomic importance in other cereals as well as in other crops (Cantrell and Reeves 2002). Genes controlling disease resistance, tolerance to abiotic stresses or synthesis of essential vitamins can be predicted by comparative genome analysis (Bennetzen 2002, Ronald and Leung 2002). Experiments can then be designed to determine whether the gene of interest has the predicted contribution or not, such as overexpression or knocking out the gene.

Although poverty and hunger is still present throughout the world, science might help to change this undesirable state through production of affordable and nutritious food. There could be less hunger- or malnutrition related deaths through understanding for example the genomes of important crops. Eventually, such problems could be those of the past, although this might take a longtime yet. Nevertheless, it is likely that there will be still differences between the parts of the world and there will be rich and poor countries as well as there are poor people in the rich countries and rich people in the poor countries.

\section{REFERENCES}

Adams M. D., S. E. Celniker, R. A. Holt et al.: The genome sequence of Drosophila melanogaster. Science 287: 2185 $-2195,2000$

Bennetzen J: Opening the door to comparative plant biology. Science 296: 60-63, 2002.

Cantrell R. P. and T. G. Reeves: The cereal of the world's poor takes center stage. Science 296: 53, 2002.

Goff S. A., D. Ricke, T.-H. Lan et al.: A draft sequence of the rice genome (Oryza sativa L. ssp. japonica) Science 296: 92-100, 2002.

Jha P., A. Mills, K. Hanson, L. Kumaranayake, L. Conteh, C. Kurowski, S. M. Nguyen, V. O. Cruz, K, Ranson, L. M. E. Vaz., S. Yu, O. Morton, J. D. Sachs: Improving the health of the global poor. Science 295: 2036 - 2039, 2002.

Ronald P. and H. Leung: The most precious things are not jade and pearls.... Science 296: 58-59, 2002.

Serageldin I.: World poverty and hunger - the challenge for science. Science 296: 54-58, 2002.

The Arabidopsis Genome Initiative: Analysis of the genome sequence of the flowering plant Arabidopsis thaliana. Nature 408: 796 - 815, 2000.

The C. elegans Sequencing Consortium Genome sequencing of the nematode C. elegans: A platform for investigating biology. Science 282: 2012 - 2018, 1998.

Yu J., S. Hu, J. Wang et al.: A draft sequence of the rice genome (Oryza sativa L. ssp. indica). Science 296: 79 $-92,2002$. 